\title{
EDWARD MUNCH EM TRADUÇÃO: ESBOÇOS E TEXTOS
}

EDVARD MUNCH IN TRANSLATION: SKETCHES AND TEXTS

Ludmila Menezes Zwick* ～* apuslynx@gmail.com

Doutora em Literatura e cultura russa (com trabalho sobre artes

visuais) pela Universidade de São Paulo e Mestra em Estética e

História da Arte pela mesma universidade.

\section{APRESENTAÇÃO}

Da extensa produção escrita de Edvard Munch (1863-1944), apresento aqui a tradução do norueguês ao português dos seguintes textos literários esboçados por ele: MM N 652, s.d., MM T 2367, de 1892, MM T 329, de 1893, MM T 2908, de 1892-1893 e MM T 2901, s.d.; são textos de página única que conservam a estrutura do original, inclusive as rasuras, a exemplo da página que se segue: 


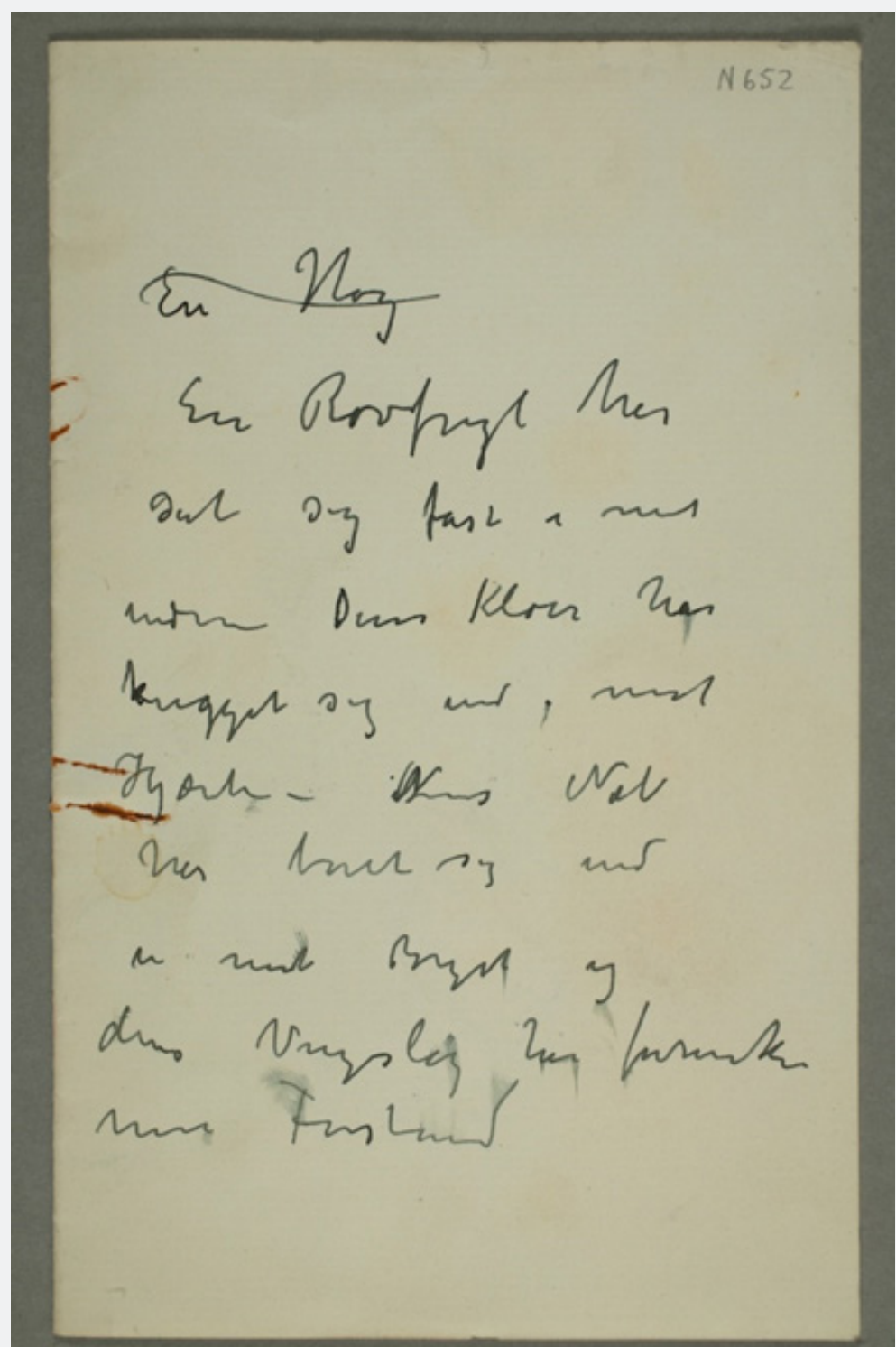

Uma águtia

Uma ave de rapina instalou-se

firmemente em meu

íntimo Suas garras

cravaram-se em meu

coração - Seu bico

enterrou-se em

meu peito e

seu bater de asas obscureceu

meu juízo

(MM N 652, s.d.)

Fig. 1. MM N 652, s.d

Disponivel em: https://www.emunch.no/HYBRIDNo-MM

N0652.xhtml 


\section{ESBOCOS E TEXTOS}

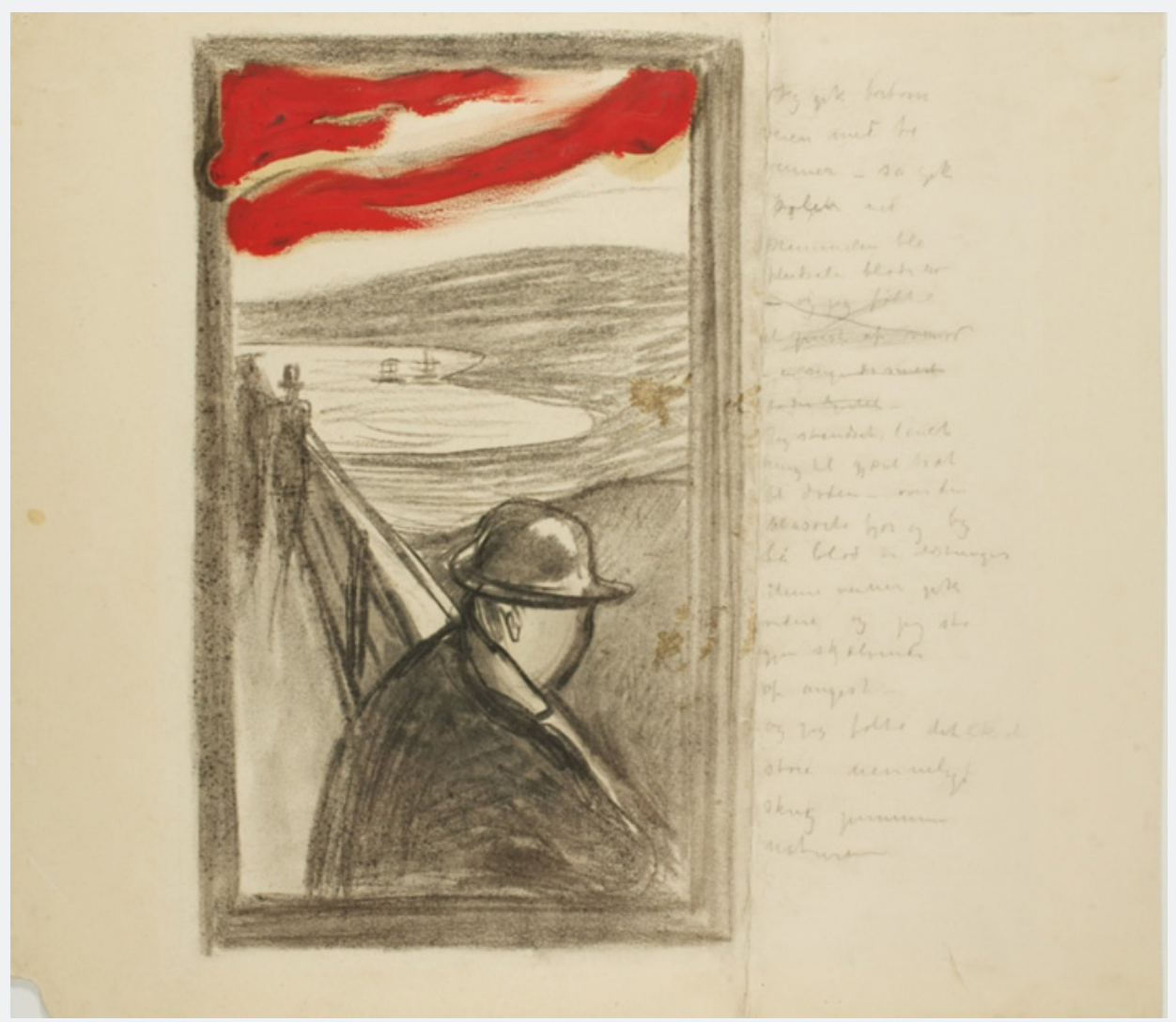

Fig. 2. MM T 2367, 1892

Disponivel em: https://www.emunch.no/HYBRIDNo-MM T2367.xhtml
Eu seguia ao longo do

caminho com dois

amigos - então o

Sol se pôs \{eu seguia\}

De súbito, o céu converteu-se

em vermelho-sangue

- e eu senti

um sopro de melancolia

- uma dor languescente

sob o coração -

Detive-me, apoiei-me

contra a cerca, fatigado

até a morte - acima do

fiorde negro-azulado e da cidade

havia sangue <em> línguas de fogo

Meus amigos seguiram

mais além e eu fique

outra vez tremendo

de angústia -

e eu senti que um

grande e infinito

grito atravessava a

natureza

(MM T 2367, 1892) 


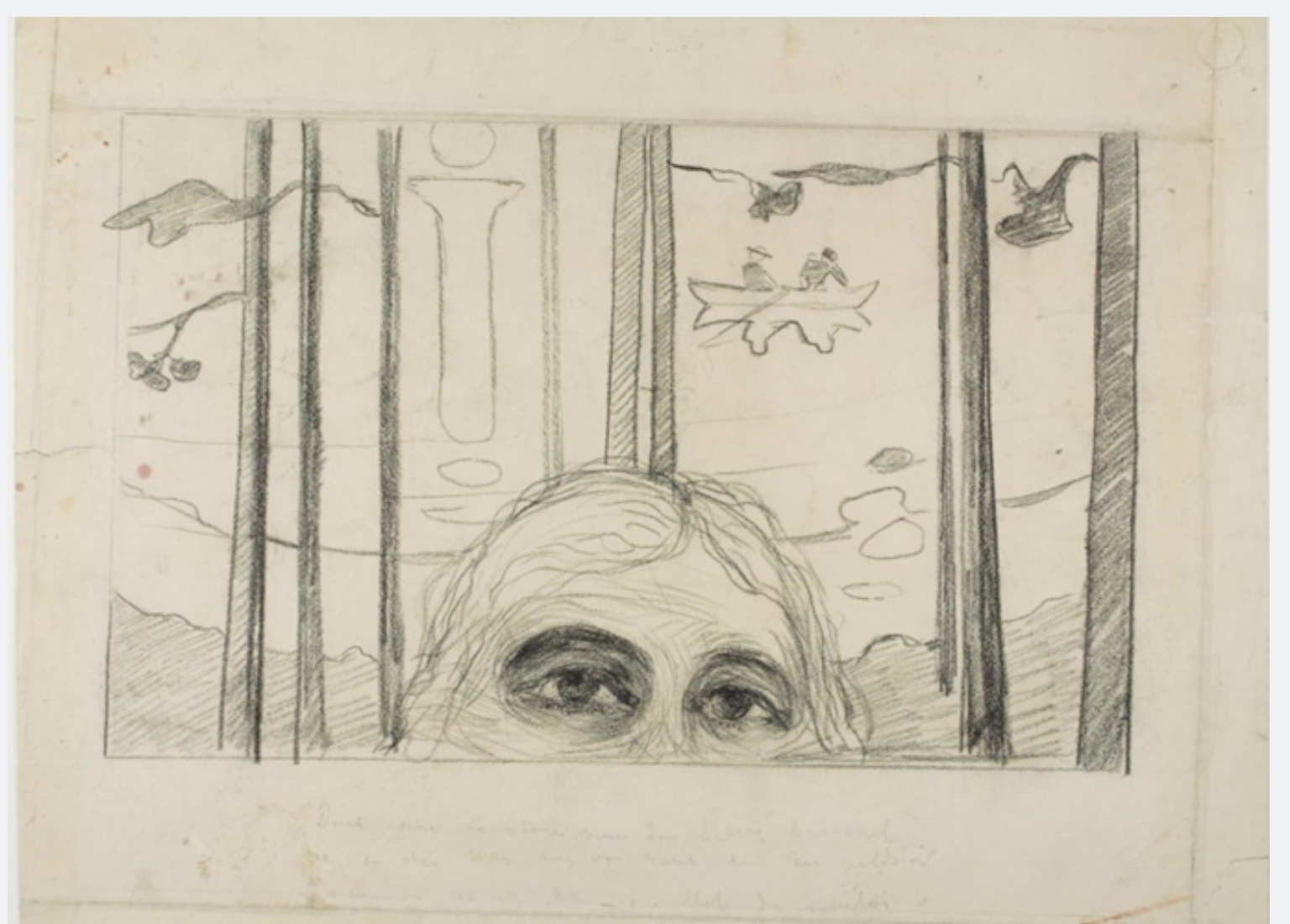

Fig. 3. MM T 329, 1893

Disponivel em: https://www.emunch.no/HYBRIDNo-MM_T0329.xhtml

Teus olhos são grandes como a metade do céu

quando estás perto de mim com teu cabelo,

que tem pó de ouro, e não vejo tua boca - apenas te vejo sorrir

(MM T 329, 1893) 


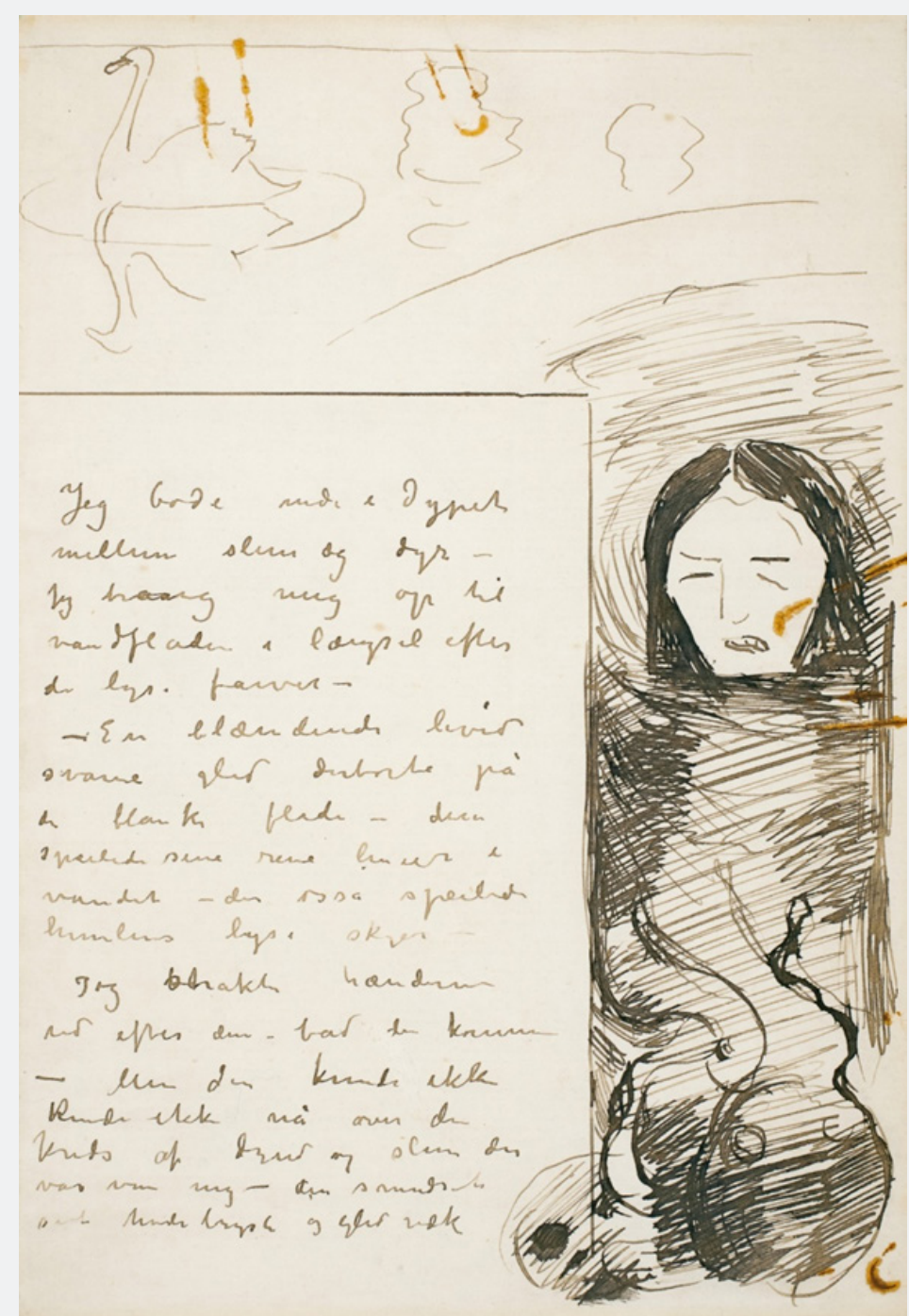

Fig. 4. MM T 2908, 1892-1893

Disponivel em: https://www.emunch.no/HYBRIDNo-MM_

T2908.xhtml
Vivi nas profundezas

entre visgos e animais -

Forcei-me até a superfície

da água ansiando pelas

cores claras -

- Um cisne ofuscantemente

branco deslizou lá

na superfície cintilante -

refletiu suas linhas puras na

água - que também refletiu

as nuvens claras do céu -

Estendi as mãos

para pegá-lo - roguei-lhe que viesse

- Mas ele não podia

Não podia passar pelo

círculo de lodo e visgo à

minha volta - sujou

seu peito branco e deslizou para longe (MM T 2908, 1892-1893) 


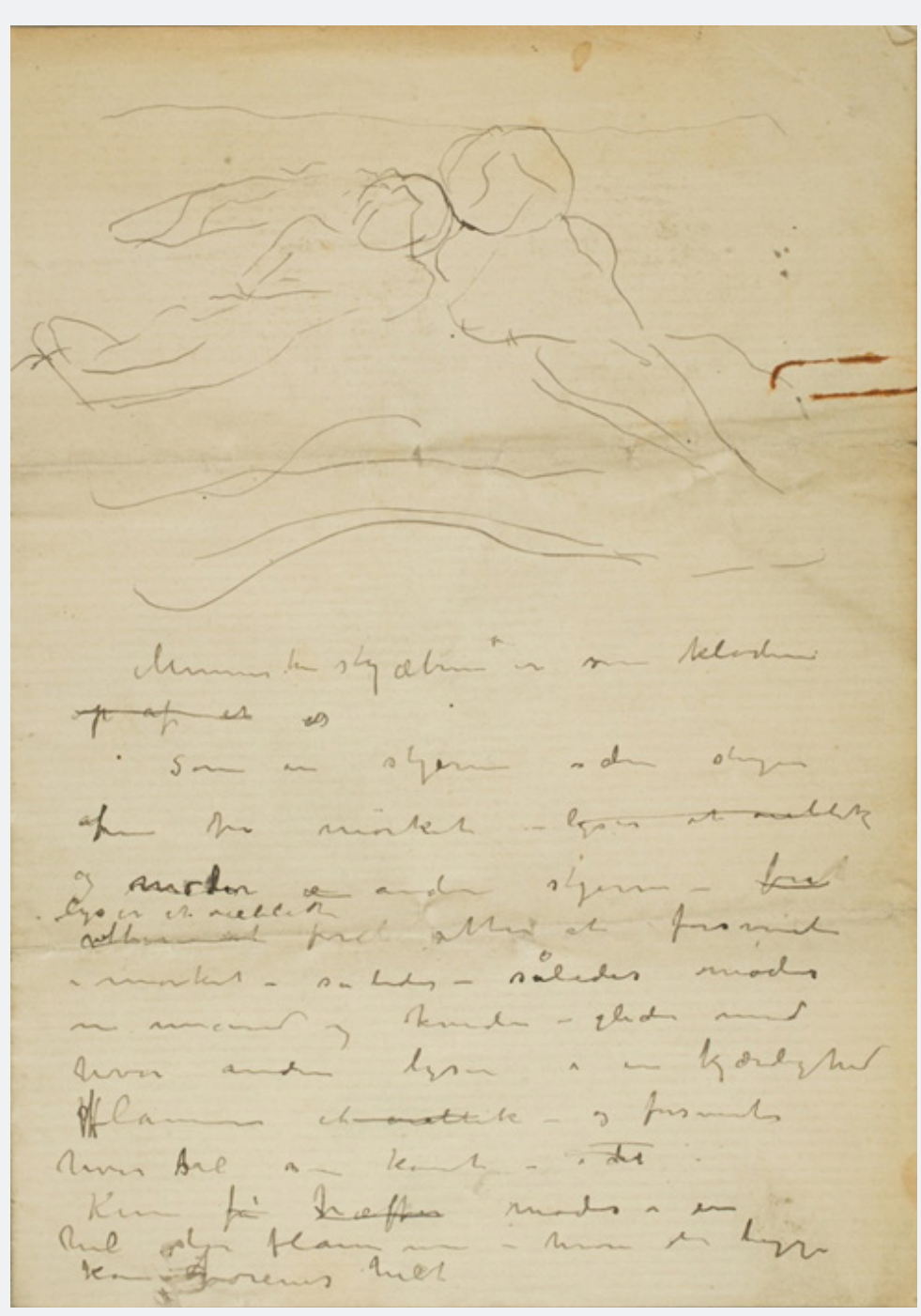

Fig. 5. MM T 2901, s.d.

Disponivel em: https://www.emunch.no/HYBRIDNo-MM_ T2901.xhtml
Os destinos humanos são como corpos celestes acima de um ...

Como uma estrela que desponta

$\{d a\}$ em meio à escuridão - britha por um instante

e encontra outra estrela -

para

brilha por um instante novamente para de novamente

desaparecer

na escuridão - deste modo - deste modo encontram-se

um homem e uma mulher - deslizam um para junto

do outro, brilham num amor

flamejam por um instante-- e desaparecem

cada qual para seu canto - enquanto

Apenas poucos teparam-se-encontram-se numa única e grande chama - em que ambos

conseguem unir-se completamente

(MM T 2901, s.d.) 


\section{REFERENCIAS}

Escritos de Edvard Munch. Acervo digital, publicado pelo Museu Munch. Coleção de Notas e textos literários. MM N 652, s.d. Disponível em: < https://www.emunch. no/HYBRIDNo-MM_N0652. xhtml > . Acesso de: abr. a maio de 2019

Escritos de Edvard Munch. Acervo digital, publicado pelo Museu Munch. Coleção de Cadernos de esboços. MM T 2367, 1892. Disponível em: <https://www.emunch. no/HYBRIDNo-MM T2367. xhtml> . Acesso de: abr. a maio de 2019.

Escritos de Edvard Munch. Acervo digital, publicado pelo Museu Munch. Coleção de Cadernos de esboços. MM T 329, 1893 Disponível em: < https://www.emunch. no/HYBRIDNo-MM_T0329 xhtml> . Acesso de: abr. a maio de 2019.

Escritos de Edvard Munch. Acervo digital, publicado pelo Museu Munch. Coleção de Cadernos de esboços. MM T 2908, 1892-1893. Disponível em: < https://www.emunch. no/HYBRIDNo-MM T2908. xhtml >. Acesso de: abr. a maio de 2019.

Escritos de Edvard Munch. Acervo digital, publicado pelo Museu Munch. Coleção de Cadernos de esboços. MM T 2901, s.d. Disponível em: < https://www.emunch. no/HYBRIDNo-MM_T2901. xhtml> . Acesso de: abr. a maio de 2019
Recebido em: 09-07-2019.

Aceito em: 23-06-2020 